\title{
Corporations Development Stage and Relationship MIS and TQM in the E- Business Era
}

\author{
Chiachia Lin \\ Department of Tourism and Leisure Management \\ WuFeng University \\ Chia-yi, Taiwan \\ 46cclin@wfu.edu.tw; 46cclin@gmail.com \\ Hungyuan Huang \\ Institute of Business Administration \\ Nanhua University \\ Chia-yi, Taiwan \\ csah6263@yahoo.com.tw
}

\author{
Wentan $\mathrm{Wu}^{*}$ \\ Institute of Leisure Recreation and Travel Management \\ ToKo University \\ Chia-yi, Taiwan \\ q2218470@gmail.com \\ * Corresponding Author \\ Huanming Chuang \\ Department of Information Management \\ National Yunlin University of Science and Technology \\ Yun-lin, Taiwan \\ chuanghm@yuntech.edu.tw
}

\begin{abstract}
This paper intends to investigate how corporations introduce and develop management information system (MIS) and total quality management (TQM) in facing the e-commerce era. Several 2014 national quality award winning firms will be used as individual cases for in-depth analysis. The development of a company's MIS and TQM will be analyzed. In this study, we discover the development of MIS and TQM for a company is closely related. Those award winning firms maintained a very high standard in the development of both MIS and TQM. This study used evaluation criteria of the national quality award as the foundation to discuss the correlation and influence of MIS and TQM. Characteristics of development processes of MIS and TQM are analyzed. In addition, by separating MIS and TQM development stages among individual cases, we discover how the development of MIS and TQM is related to each other.
\end{abstract}

Keywords- management information system; total quality management

\section{INTRODUCTION}

In many developed countries, national quality awards are established to promote the total quality management (TQM). For example, there are U.S. National Quality Award, Japan National Quality Award (also call Deming Award), and Taiwan National Quality Award. In these awards granted, the usage of information for project is included. Information clearly plays an important role in quality management.

Management information system (MIS) can reduce cost, improve productivity, promote support system and implement organizational change for organizations. As market competition intensifies, information system not only can help enterprises to enhance above-mentioned effectiveness, but also strengthen enterprise's overall competitiveness. So, increasingly enterprises found that the information technology and information system are key success factors of quality management. Thus, through the implementation of management information system, enterprises should be able to better execute total quality management.

Taiwan National Quality Award (TNQA) is the top honor awarding to enterprises with overall business quality in Taiwan. In 1990, The Ministry of Economic Affairs established the TNQA to help enterprises upgrade overall business standard and improve international image. Initially the award was limited to manufacturers only in manufacturing industry, starting in 1995 the award was applicable to non-manufacturing industry. Based on the TNQA award category, this study will investigate those TNQA winning manufacturers in 2014 to further explore the following items:

1. The related impact of MIS on TQM.

2. MIS development process related to the development process characteristics of TQM in various development stages.

3. According to the characteristics of each category of TNQA and by using specific case examples to distinguish the usage of MIS and the development stage of TQM and further identify the relevance of MIS and TQM development.

\section{The DeVElopment Stage And Mode OF MIS AND TQM}

In response to the e-business era, information system (IS) can be integrated into the different business functions and improve the efficiency of various processes. Further, it can accumulate experience through information systems. The role of IS had been promoted from traditional data processing to generating of strategic competitive advantage. The factors making the implementation of TQM successful include management capability of quality information, production rationalization, and automation.

Whether IT or IS produces great impact on the organization. Both are covered by the broad range of MIS. 
This study intends to explore the relationship between MIS and TQM especially the objects included in MIS.

MIS theory was proposed by Nolan as early as 1979 . This theory suggests that the organization using IT is through a series of growth process. This process can be divided into six stages where each stage has its own characteristics. The response to the growth of computer applications would reflect different degree of control at every stage. The basic premise is an organization must go through prior stage to enter the next stage. Therefore, this development model can be used to diagnose the current stage of an organization. We can project possible future conditions and thus provide planners suggestions for consideration.

In addition to the above six-stage theory, Venkatraman had also proposed a five-stage theory on the application and development of IT. The initial stage begins with the easy part of implementation of computer-based functioning. The final stage ends when the entire enterprise is fully computerized across the board. The development processes are cumulative growth and evolving level by level. In the beginning, an organization may not work efficiently. But if IT can provide a better solution, the original model should be abandoned. Switching to the new programming arrangements in an organization would cause a substantial adjustment in operating procedures. Further, the relationship between enterprises and enterprises (Extranet) also need to adapt their cooperation with the new IT advancement. This stage is called revolution level. Finally, the organization's scope of business will change with some expansion, some innovation, some disappearing. The potential benefits for an organization will increase along with a higher degree of corporate restructuring.

\section{ANALYSIS OF THE RELATIONSHIP BETWEEN MIS AND TQM}

This paper used the award category of TNQA to analyze and compare the basis of connecting development between MIS and TQM. The major concept is to apply the nine award categories of TNQA coupled with current implementation status of MIS and TQM in enterprises to judge their development stage of MIS and TQM. For corporation had higher development stage of MIS, its TQM is supposed to have developed better than other companies. Some case studies were investigated accordingly.

According studies, TQM can be divided into five stages of development. In this study, a five-stage development of TQM was used as the basis for analysis and comparison. The intention is to define the development of MIS in a business and how MIS is used to support their quality management operation and development characteristics of each stage.

\section{CASE ANALYSIS}

This study selected the vendors from whom applied for 2014 TNQA and passed the first round judgment as the objects for case analysis. Among them, one award-winning company in manufacturing industry and one in service sectors; one non- winning company in manufacturing industry and one in service sectors too. Based on information provided, Table 1 summarized case analysis results:

In the process of conducting case analysis, the following points are found:

1. Regarding the theme on research and development and social responsibility, business has less planning in MIS application in this respect.

2. On the development of thematic scope of TQM, many achievements in the development is due to the use of MIS. This implies that MIS affects the development of TQM.

3. In addition to the development of TQM, the Case 1 and Case 2 enterprises had more comprehensive MIS development than the other two companies. In fact, these two enterprises won TNQA in 2009.

4. The historical development of MIS and TQM for case 1 company matched very well with the theoretical perspective of MIS and TQM development stages. Manufacturers are pioneers to implement TQM and introduce MIS. It may be the reason causing this phenomenon.

5. In terms of customer service, case studies had shown that most companies still used traditional approach to provide service. When compare with different industries, information services industry are more skilled at using MIS to enhance customer service quality. Some examples are: use of remote detection, diagnose customer's problem on-line immediately, resolute incidents speedily rather than sending representative to the scene.

It can be seen from Table I that the overall development of a comprehensive assessment of the development stage. Companies reached the same development stage in TQM and MIS. The TNQA award winning companies are at the stage IV. 
TABLE I. CONSOLIDATED RESULTS OF CASE STUDIES

\begin{tabular}{|c|c|c|c|c|c|c|c|c|c|}
\hline \multirow{2}{*}{\multicolumn{2}{|c|}{ Case status }} & \multicolumn{4}{|c|}{ TQM } & \multicolumn{4}{|c|}{ MIS } \\
\hline & & \multirow{2}{*}{$\begin{array}{c}\text { Case1 } \\
\mathrm{IV}\end{array}$} & \multirow{2}{*}{$\begin{array}{c}\text { Case2 } \\
\text { IV }\end{array}$} & \multirow{2}{*}{$\frac{\text { Case3 }}{\text { III }}$} & \multirow{2}{*}{$\frac{\text { Case4 }}{\text { III }}$} & \multirow{2}{*}{$\begin{array}{c}\text { Case1 } \\
\text { IV }\end{array}$} & \multirow{2}{*}{$\begin{array}{c}\text { Case2 } \\
\text { IV }\end{array}$} & \multirow{2}{*}{$\frac{\text { Case3 }}{\Pi}$} & \multirow{2}{*}{$\begin{array}{c}\text { Case4 } \\
\Pi\end{array}$} \\
\hline \multirow{9}{*}{ 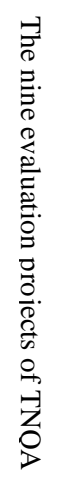 } & Business philosophy goals and strategies & & & & & & & & \\
\hline & Organization and operation & IV & IV & II & III & IV & IV & $\Pi$ & II \\
\hline & Human development and application & IV & IV & II & III & IV & IV & II & II \\
\hline & IM and application & $\mathrm{IV}$ & IV & II & III & IV & $\mathrm{V}$ & III & III \\
\hline & Research and development & IV & III & III & III & IV & III & II & III \\
\hline & Quality guarantee & IV & IV & III & $\Pi$ & IV & IV & III & III \\
\hline & Customer service & IV & IV & III & III & IV & $\mathrm{V}$ & III & II \\
\hline & Social responsibility & IV & III & $\Pi$ & $\Pi$ & IV & III & $\Pi$ & $\Pi$ \\
\hline & TQM performance & $\mathrm{V}$ & $\mathrm{V}$ & III & III & IV & $\mathrm{V}$ & III & III \\
\hline \multicolumn{2}{|r|}{ Overall assessment of development stage } & IV & IV & III & III & IV & IV & III & III \\
\hline \multicolumn{2}{|r|}{ Receive award } & yes & yes & no & no & & & & \\
\hline
\end{tabular}

\section{SURVEY OF EXPERT OPINIONS}

In addition to case studies, this study also examined the relationship between MIS and TQM from a questionnaire survey for expert opinions. Fifteen surveys were received. Among those fifteen experts, there are six professors from academia, five executives from industry, and four government officials. The questionnaire included two broad categories:

Investigation on experts belief to what extent the use of MIS can enhance TQM benefit. A rubric score between 1 and 5 is summarized as shown in Table II. In addition, an open suggestions column is provided to gather relevant recommendations from experts.

TABLE II. THE QUESTIONNAIRE OF USING MIS TO ENHANCE THE FRIENDLINESS OF TQM

\begin{tabular}{|c|c|c|c|c|c|}
\hline Score & 1 & 2 & 3 & 4 & 5 \\
\hline 1. Whether the company's overall computerization will help enhance quality management & 0 & 2 & 3 & 4 & 6 \\
\hline 2.Company's computerization level will affect its quality management & 0 & 1 & 3 & 5 & 6 \\
\hline 3.The phase-in on MIS / TQM will benefit companies gradual implementation & 0 & 1 & 4 & 4 & 6 \\
\hline $\begin{array}{l}\text { 4.If MIS is included as one of the nine award categories of TNQA, will it help to select the } \\
\text { representative enterprise for TQM }\end{array}$ & 0 & 2 & 4 & 4 & 5 \\
\hline $\begin{array}{l}\text { 5.Do you think the inclusion of MIS as an award category of TNQA to provide reference } \\
\text { for vendors would benefit companies }\end{array}$ & 0 & 2 & 3 & 5 & 5 \\
\hline
\end{tabular}

Note: The following indicate the meaning of each score:

"1": No benefit (impact)、 "2": Benefit (impact) is a little、 "3": Helpful (impact)

"4": Have benefit (impact)、 "5": Benefit (impact) significantly

\section{CONCLUSIONS AND FUTURE RESEARCH DIRECTIONS}

\section{A. Conclusion}

The Development of MIS caused many impacts on businesses. The impact level is almost comprehensive. This paper explored the impact of MIS on the TQM through looking into the characteristics in development stages of MIS and TQM. The following conclusions are found:

1) MIS can help the development of process-oriented activities. Using MIS can integrate operation processes and information in an organization. MIS can help achieve TQM objectives in TQM related activities.

2) This paper proposed the phase-in development model that can be used to diagnose a company's development of MIS and TQM. Companies can use this as a planning framework to consider assistance of MIS in TQM operation.

3) Overall speaking, MIS can improve TQM effectiveness. MIS planning should be in accordance with industry to cope with the nature of an overall consideration of the development of enterprises.

4) In the case studies we found that manufacturers best fit the MIS/TQM operation characteristics in development stage proclaimed in this article.

5) Corresponding to MIS as one of TNQA evaluation categories, experts had divergent views on whether to provide award referees with MIS information and TQM execution in enterprises.

Possible causes are: (1) the provided information about MIS is incomplete, (2) operations as a whole vs. sub-sector can generate different effects. 
The statistical results from the cases analysis can be seen in the overall assessment of the development stage. The industry's development of both TQM and MIS is at the same stage for the award winning companies.

\section{B. Suggestions and Future Research Directions}

1) This paper listed the corresponding development stage of TQM and MIS based on the ideas of stage wide development and functional classification. It also followed those nine awarding categories of TNQA related to MIS Future studies can continue more in-depth and circumspect consideration regarding MIS related items.

2) This paper used case study approach to analyze TQM and MIS matching development items and actual application status of its operations. Case Analysis was limited to the difficulty of obtaining data, therefore, future studies can expand research objects of study in order to achieve more precise results.

3) Future studies can further explore if the development of TQM did not go hand in hand with the MIS of the company, would it cause differences in the company's overall efficiency? For example, a company reached the fourth stage in TQM but developed to the second stage in MIS.

\section{REFERENCES}

[1] Badiru, A. B., "A System Approach to Total Quality Management," Industrial Engineering, Vol. 22, 1990, No. 3, pp. 33-36.

[2] Chiang, C. H., "The structure of quality information system in a computer integrated manufacturing environment," Computers \& Industrial Engineering, Vol. 15, 1988, No. 1-4, pp. 338-343.

[3] Chiang, J. K., Pfeifer, T., Innovative Software Technologies for Quality Management, " in "Manufacturing Excellence $\sim$ the Competitive edge . Pfeifer, Eversheim, Konig and Weck ed., Chapman \& Hall, New York, 1994.

[4] Chou, H. K, Evaluation of projects, "information management and application of the assessment focus. Corporate Synergy Development Center National Quality Award Evaluation Committee Working Group, "National Quality Award for the sixth member of the consensus panel pre-conference seminar-cum-trial" data., 2001.

[5] Clarke, S., Recommended blogs for art reviews -new ARLIS publication. Educational Technologies Librarian, The Center for Instructional Technology, James Madison University, New York, 2008.

[6] Cortada, J. W., TQM for information systems management. McGraw-Hill, New York, 1995.
[7] Crosby, P., Quality is free. New York, Mentor, 1980.

[8] Davis, G. B. and Olson, M. H., Management information system: Conceptual foundations, structure and development, 2nd ed., McGraw-Hill, New York, 1985.

[9] Fang, W. C., Management information systems. Tingmao Publish Company, Taipei, 2006.

[10] Gabor, A., The man who discovered quality. New York : Times Books, 1990.

[11] George, R., Introduction to Management Information System. Hwa Tai Culture Publishing Company, Taipei, 2008.

[12] Gitlow, H., Gitlow, S., Oppenheim, A., and Oppenheim, R., Tools and methods for the improvement of quality. Homewood, IL, Irwin , 1989.

[13] Kalakota, R. and Robinson, M., E-Business : Roadmap for success.1st ed., Addison-Wesley, USA, 1999.

[14] Kao, J. C. , Mei-Cheng Lan translated, E-business 8 prototype. 1st edition. Linking Book Publishing Co., Taipei, 2001.

[15] Lin, C. C., "A study of the changes in the role and managing of accounting personnel when ERP is implemented by a corporation adapting to the E-business," Diwan Journal of Management, Vol. 2, 2007No. 1, pp. 77-97.

[16] Lin, K. F., "Integrating TQM / ISO9000 to improve the quality of the Road," International Quality Conference, pp.1-11, 1994.

[17] Lin, S. L., The study of E-business build competitive edge for enterprises," Institute of International Business, National Taiwan University. Master thesis, 2002.

[18] Lin, Y. F., Promote the TQM critical success factors. Ministry of Economic Affairs Industrial Development Bureau, National Quality Award Evaluation Committee Working Group, "National Quality Award lecture tour (2), 1995.

[19] Luan, P., Chen, Y. J. and Luo, K. Y., Electronic Commerce. 5th ed., Tsang Hai Book Publishing Co, Taipei, 2007.

[20] Martin, L. L., Organization and management of social service agencies - - Theory and practice of Total Quality Management. Yang Chih Culture Publishing Company, Taipei, 1997.

[21] Mossard, G.. R., “A TQM Technical Skills Framework,” Journal of Management Science Policy Analysis, Vol. 8, 1991, No. 3/4, pp. 223-246.

[22] Nolan, R. L., "Managing the crises in data processing," Harvard Business Review, Vol. 57, 1979, No. 2, pp. 115-126.

[23] Song, K., Fan, Z. Q., Guo, H. Z., JI, Y. P. and Chen, M. T., Management information systems. Hwa Tai Culture Publishing Company, Taipei, 1999.

[24] Tsao C. C., Operation and management of E-commerce. 1st ed, All Chinese science and technology, Taipei, 2003.

[25] Venkatraman, N., "IT-Enabled business transformation : From automation to business scope redefinition," Sloan Management Review, Vol. 35, 1994, No.2, pp. 73-87.

[26] Ward, J. M., "Integrating Information System into Business Strategies," Long Range Planning, Vol. 20, 1987, No. 3, pp. 19-29. 